\title{
Phase diagram of the spin quantum Hall transition
}

\author{
V. Kagalovsky* and D. Nemirovsky \\ Shamoon College of Engineering, Bialik/Basel St., Beer-Sheva 84100, Israel \\ E-mail: demitryn@sce.ac.il
}

Received May 17, 2018, published online September 26, 2018

\begin{abstract}
We study a system which can be realized in a dirty, gapless superconductor in which time-reversal symmetry for orbital motion is broken, but spin-rotation symmetry is intact. We present a phase diagram in a phase-space of spin Hall conductance $\epsilon$ and energy of quasiparticles $\Delta$. It exhibits a direct transition between two insulating phases with quantized Hall conductances of zero and two for the conserved quasiparticles when $\Delta=0$. The energy of the quasiparticles acts as a relevant symmetry-breaking field at the critical point, which splits the direct transition into two conventional plateau transitions. We use updated correct values of the critical exponents to define these two critical lines as $\epsilon \sim \pm \Delta^{6 / 7}$.
\end{abstract}

Keywords: spin quantum Hall effect, class C, critical exponents, phase diagram.

\section{Introduction}

Anderson localization of a quantum particle [1] is an intensive research field [2]. One of its central research directions is the physics of Anderson transitions [3], quantum critical points tuned by disorder. These include metalinsulator transitions and transitions of quantum Hall type separating distinct phases of topological insulators.

From the theoretical point of view, symmetries play a central role in determination of universality classes of critical phenomena. This idea was applied to Anderson localization in $[4,5]$, where ten distinct symmetry classes were identified. In three of these classes, classes A, C, and D, the time-reversal invariance is broken, and there is a possibility for a quantum Hall transition in two dimensions. The transition in class A is the usual integer quantum Hall transition in a two-dimensional (2D) electronic system in a strong perpendicular magnetic field (see [6] for a review). Class $\mathrm{C}$ is one of the four Bogoliubov-de Gennes classes which describe transport of quasiparticles in disordered superconductors at a mean field level, and possess the particle-hole symmetry. In this class the spin-rotation invariance is preserved, the quasiparticles have conserved spin, and one can study spin transport. The corresponding Hall transition is known as the spin quantum Hall (SQH) transition [7,8], at which the system exhibits a jump in the spin Hall conductance from 0 to 2 in appropriate units.

In this brief report, we present a phase diagram for a system belonging to class $\mathrm{C}$ using updated correct values of the critical exponents. We show that in the presence of a symmetry-breaking field (which breaks spin-rotation invariance) the transition occurs in two stages, and two critical lines are defined by the new critical exponent 6/7.

\section{The model}

A scattering theory description of Anderson localization and Anderson transitions in terms of random network models was introduced in [9]. The resulting networks are chiral, reflecting the breaking of timereversal invariance in strong magnetic fields. The simplest such model is the the ChalkerCoddington (CC) model originally proposed to describe the integer quantum Hall (IQH) effect [10]. In this model, electrons move along unidirectional links forming closed loops in analogy with semi-classical motion on contours of constant potential. Scattering between links is allowed at nodes in order to encode tunneling through saddle point of the potential landscape. A natural generalization of the network model includes spin. It is achieved by allowing each link to carry two channels (both in the same direction). Two states can mix on the link but scatter separately at the node.

The symmetry class $\mathrm{C}$ was mapped onto generalized CC model [7] by allowing $S U(2)$ matrices on the links which preserve spin-rotation invariance (see Fig. 1). Scattering at the nodes is parameterized by $\epsilon \pm(1 / 2) \Delta$. The value of $\epsilon$ determines the Hall conductance of the system, as measured at short distances: varying $\epsilon$ drives the model through the delocalization transition (in this sense $\epsilon$ corresponds to a Fermi level as in the standard CC model). A non-zero value for $\Delta$ breaks spin-rotation invariance, and in fact changes the universality class for the transition.

* Also at Max-Planck-Institut für Physik komplexer Systeme, Nöthnitzer Str., Dresden, Germany.

(C) V. Kagalovsky and D. Nemirovsky, 2018 


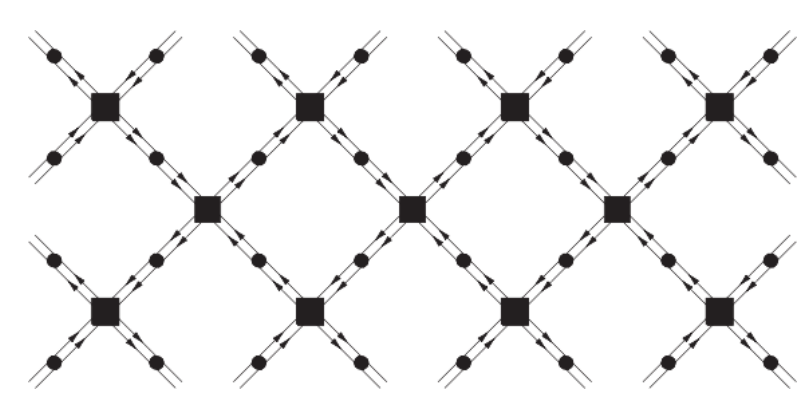

Fig. 1. Two-channel chiral network model. Dots represent scattering matrices on the links and squares represent the nodal scattering matrices.

Numerical calculations for a very long system of particular width $M$ produce a localization length (as the inverse of the smallest positive Lyapunov exponent $\lambda_{M / 2}$ ) which staisfies a two-parameter scaling assumption

$$
\frac{\xi_{M}}{M}=f\left(\epsilon^{v} M, \Delta^{\mu} M\right)
$$

which allows to find the values of two critical exponents. These exponents describe the divergence of two corresponding thermodynamic localization lengths $\xi_{1} \sim|\epsilon|^{-v}$ and $\xi_{2} \sim|\Delta|^{-\mu}$, when a critical point $\epsilon=\Delta=0$ is approached along $\epsilon$ and $\Delta$ axes.

\section{Phase diagram}

In the original paper [7] a broad range of $\epsilon \in[0,1]$ was used (including the values of $\epsilon$ far from the critical point), and the result was $v \approx 1.12$. In a more recent study [11] the authors used only data for $\epsilon<0.05$ (very close to the critical point), and obtained $v \approx 1.335$, in excellent agreement with the analytical prediction $v=4 / 3$ [12].

A numerical result found in [7] for a second critical exponent $\mu \approx 1.45$ was in a good agreement with analytical prediction 3/2 [12]. Both results were recently significantly corrected [13]. Percolation mapping of [12] was used to extract analytical value $\mu=8 / 7$. Numerical simulations used a different (from [7]) approach. Instead of breaking spinrotation invariance in the nodes of the network by introducing parameter $\Delta$, extra random phases with zero mean were defined on the links, and their variance $p$ was used as a symmetry-breaking parameter. Without symmetry-breaking perturbations, all Lyapunov exponents of the transfermatrix product are doubly degenerate due to the presence of timereversal invariance (Kramers degeneracy). It was suggested in [7] that when the time-reversal symmetry is broken by a small perturbation, the renormalized localization length and the deviation from Kramers degeneracy (the difference between the two smallest positive Lyapunov exponents multiplied by the circumference $M$ ) exhibit scaling behavior characterized by the same exponent. This idea was further supported in $[14,15]$. It turned out that the deviation from Kramers degeneracy is a superior way to extract criti-

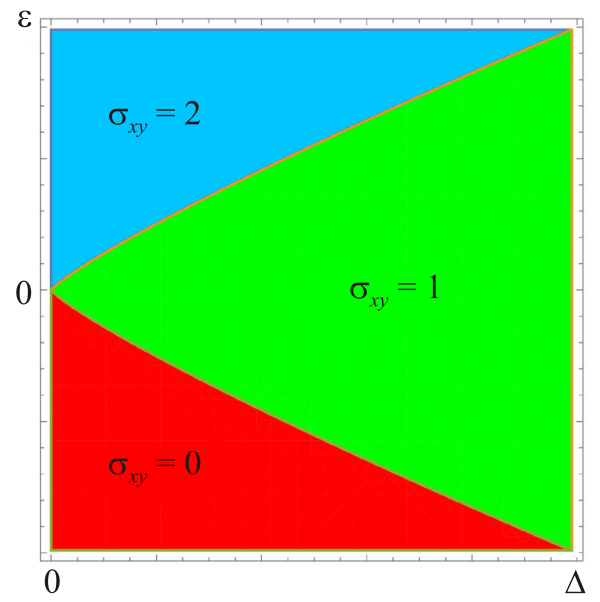

Fig. 2. (Color online) The phase diagram for a spin quantum Hall effect, exhibiting three phases with spin Hall conductivities $\sigma_{x y}^{s}=0, \quad \sigma_{x y}^{s}=1$, and $\sigma_{x y}^{s}=2$, seprated by critical lines $\epsilon \sim \pm \Delta^{6 / 7}$.

cal exponents in this case, since we know its exact zero value at the critical point. It has been shown in [13] that both perturbations breaking spin-rotation invariance act as a random Zeeman field and must have the same critical exponent $\mu$. The numerical results using deviations from Kramers degeneracy produced $\mu \approx 1.15$ in excellent agrement with analytical prediction $\mu=8 / 7 \approx 1.14$. We believe that the reason for the discrepancy of the previous and recent numerical results is that only large values of $\Delta$ were used in [7]. Indeed, in that paper it was impossible to resolve two separate critical states for $\Delta<0.5$.

Now finally we can write two-parameter scaling with correct critical exponents

$$
\frac{\xi_{M}}{M}=f\left(\epsilon^{4 / 3} M, \Delta^{8 / 7} M\right)
$$

On the critical lines the scaling function is $M$-independent. This unambiguously defines critical curves on the phase diagram as $|\epsilon| \sim \pm \Delta^{\mu / v}= \pm \Delta^{6 / 7}$. We present a phase diagram in Fig. 2.

\section{Acknowledgments}

This work was supported by the SCE internal grant EXR01/Y17/T1/D3/Yr1. VK is grateful for hospitality of MPI-PKS, Dresden, where major part of this work was done.

1. P.W. Anderson, Phys. Rev. 109, 1492 (1958).

2. E. Abrahams, 50 Years of Anderson Localization, International Journal of Modern Physics: Condensed Matter Physics, Statistical Physics, Applied Physics, World Scientific (2010).

3. F. Evers and A.D. Mirlin, Rev. Mod. Phys. 80, 1355 (2008).

4. A. Altland and M.R. Zirnbauer, Phys. Rev. B 55, 1142 (1997).

5. M.R. Zirnbauer, J. Math. Phys. 37, 4986 (1996). 
6. B. Huckestein, Rev. Mod. Phys. 67, 357 (1995).

7. V. Kagalovsky, B. Horovitz, Y. Avishai, and J.T. Chalker, Phys. Rev. Lett. 82, 3516 (1999).

8. T. Senthil, J.B. Marston, and M.P.A. Fisher, Phys. Rev. B 60, 4245 (1999).

9. B. Shapiro, Phys. Rev. Lett. 48, 823 (1982).

10. J.T. Chalker and P.D. Coddington, J. Phys. C: Solid State Phys. 21, 2665 (1988).

11. H. Obuse, A.R. Subramaniam, A. Furusaki, I.A. Gruzberg, and A.W.W. Ludwig, Phys. Rev. B 82, 035309 (2010).

12. I.A. Gruzberg, A.W.W. Ludwig, and N. Read, Phys. Rev. Lett. 82, 4524 (1999).

13. S. Bhardwaj, I.A. Gruzberg, and V. Kagalovsky, Phys. Rev. $B$ 91, 035435 (2015).

14. V. Kagalovsky, B. Horovitz, Y. Avishai, and J. Chalker, Ann. Phys. (Leipzig) 8, SI (1999).

15. V. Kagalovsky, B. Horovitz, Y. Avishai, and J. Chalker, Physica E 9, 352 (2001), Proceedings of an International Workshop and Seminar on the Dynamics of Complex Systems.

\section{Фазова діаграма спінового квантового переходу Холла}

\section{В. Кагаловський, Д. Неміровський}

Вивчено систему, яка реалізується в брудних, безщілинних надпровідниках, в яких порушена симетрія звернення часу орбітального руху, але не зачеплена симетрія спінового обертання. Представлено фазову діаграму в площині спінової холлівської провідності $\epsilon$ та енергії квазічастинок $\Delta$. Система зазнає прямий перехід між двома непровідними фазами, які відповідають квантованим холлівським провідностям нуль і два для квазичастинок, що зберігаються, при $\Delta=0$. Енергія квазічастинок діє як характерне поле, що порушує симетрію в точці переходу, яке розщеплює прямий перехід на два послідовних перехода типу плато. Використовано скориговані правильні значення для критичних індексів для визначення цих двох критичних ліній як $\epsilon \sim \pm \Delta^{6 / 7}$.

Ключові слова: спіновий квантовий ефект Холла, клас С, критичні індекси, фазова діаграма.

\section{Фазовая диаграмма спинового квантового перехода Холла}

\section{В. Кагаловский, Д. Немировский}

Изучена система, которая реализуется в грязных, бесщелевых сверхпроводниках, в которых нарушена симметрия обращения времени орбитального движения, но не затронута симметрия спинового вращения. Представлена фазовая диаграмма в плоскости спиновой холловской проводимости $\epsilon$ и энергии квазичастиц $\Delta$. Система испытывает прямой переход между двумя непроводящими фазами, соответствующими квантованным холловским проводимостям нуль и два для сохраняющихся квазичастиц, при $\Delta=0$. Энергия квазичастиц действует как характерное поле, нарушающее симметрию в точке перехода, которое расщепляет прямой переход на два последовательных перехода типа плато. Использованы скорректированные правильные значения для критических индексов для определения этих двух критических линий как $\epsilon \sim \pm \Delta^{6 / 7}$.

Ключевые слова: спиновый квантовый эффект Холла, класс С, критические индексы, фазовая диаграмма. 